\title{
Association of Obesity, Parity, and History of Knee Injury with Knee Osteoarthritis in Female
}

\author{
Ade Triyadi, ${ }^{1}$ Riardi Pramudiyo, ${ }^{2}$ Januarsih Iwan A. R. ${ }^{3}$ \\ ${ }^{1}$ Faculty of Medicine Universitas Padjadjaran, ${ }^{2}$ Department of Internal Medicine Faculty of \\ Medicine Universitas Padjadjaran/Dr. Hasan Sadikin General Hospital Bandung, ${ }^{3}$ Department of \\ Anatomy and Cell Biology, Faculty of Medicine, Universitas Padjadjaran
}

\begin{abstract}
Background: Osteoarthritis is the most joint disorder among elderly. There are a lot of risk factors of knee osteoarthritis. Obesity and high frequent of parity can increase the load on knee joint. Knee injury also decreases the stability of knee joint on bearing body load. This study was conducted to observe the association of obesity, parity $\geq 3$ times and history of knee injury with the occurrence of knee osteoarthritis in female aged $>50$ years old.

Methods: Case control design was chosen in this study. Female patients with age $>50$ years were recruited by consecutive sampling from rheumatology clinic at Dr. Hasan Sadikin General Hospital Bandung. Data were collected from August to September 2013. Minimal sample size was 60 samples calculated by rule of thumb formula. Obesity was measured by body mass index (BMI). Parity and history of knee injury were assessed by questionnaire. Those variables were analyzed by logistic regression method.

Result: Obesity did not associate with knee osteoarthritis in this study, p=0.549 (odd ratio (OR) 1.32, 95\% confidence interval (CI) 0.52-3.32). Parity was associated with knee osteoarthritis in this study $\mathrm{p}=0.001$ (OR 4.7, 95\% CI 1.89-11.68). History of knee injury was associated with knee osteoarthritis in this study, $\mathrm{p}=0.001$ (OR 6.19, 95\% CI 2.01-18.99).
\end{abstract}

Conclusions: Parity $\geq 3$ times and history of knee injury were associated with the occurrence of knee osteoarthritis. Obesity was not associated with the occurrence of knee osteoarthritis. [AMJ.2015;2(4):492-6]

Keywords: Knee injury, knee osteoarthritis, obesity, parity

\section{Introduction}

Osteoarthritis is the most joint disorder among elderly. Worldwide, it is estimated to be the fourth of leading causes of disability. ${ }^{1}$ Weight bearing joint (especially knee joint) is often involved in the disease process. Currently, World Health Organization (WHO) estimated that $9.6 \%$ of male and $18 \%$ of female have painful osteoarthritis worldwide. $^{2}$ In the Asia-Pacific region, the prevalence of knee osteoarthritis was 7.5\% in China, 5.78\% in rural India, and $10.20 \%$ in Bangladesh. ${ }^{3}$ Osteoarthritis has a substantial disease burden and affects quality of life. For instance, 1-2 million elderly in Indonesia have disabilities because of osteoarthritis. ${ }^{4}$ People with osteoarthritis have more difficulties to perform activities of daily living that depend significantly more on family and friends for assistance and spend more money on health care. $^{5}$

There are a lot of risk factors to develop knee osteoarthritis such as older age, female, genetic susceptibility, race factors, hard worker (high intense to weight bearing work), athlete, knee mal-alignment, knee injury and obesity. ${ }^{6}$ Parity $\geq 3$ times is also a risk factor of knee osteoarthritis. ${ }^{78}$ This study was conducted to observe the association of knee osteoarthritis with obesity, parity $\geq 3$ times and history of knee injury. These risk factors were chosen to be analyzed in this study because mechanical forces exerted on the joint are a significant cause of knee osteoarthritis and one of the most modifiable risk factors. Since these factors are modifiable risk factors, the morbidity of knee osteoarthritis will be reduced if these factors can be avoided

Correspondence: Ade Triyadi, Faculty of Medicine, Universitas Padjadjaran, Jalan Raya Bandung-Sumedang Km.21, Jatinangor, Sumedang, Indonesia, Phone: +6285759754147 Email: ade3yadi@gmail.com 


\section{Methods}

Female patients aged $>50$ years were recruited from rheumatology clinic at Dr. Hasan Sadikin General Hospital Bandung. Data were collected from August to September 2013 and the samples were recruited by consecutive sampling. Case control method was chosen as study design. Cases were female aged $>50$ years old, come to clinic and were diagnosed with knee osteoarthritis by physicians. Controls selected who come to the clinic but did not diagnose knee osteoarthritis by physician.

The inclusion criteria were patients who come to the Rheumatology Clinic at Dr. Hasan Sadikin General Hospital Bandung, aged >50 years and female. Besides, the exclusion criteria who did not want to participate in this study had genetic susceptibility to osteoarthritis who had history of weight bearing worker or athlete.

Samples were interviewed using structured questionnaires to determine medical history, including history of knee injury and number of life births. Height and weight were measured two times to confirm the result.

To determine the risk factor of knee osteoarthritis, only three factors included as independent variable were selected. Obesity measured by body mass index (BMI), Kementrian Kesehatan Republik Indonesia (KemenKes RI) criteria of BMI was selected in this study. The BMI $>27$ was defined as obesity. 9 Parity was classified as woman who has complete $\geq 3$ times pregnancies and woman who has complete $<3$ pregnancies, which the data were obtained by interview. History of knee injury, the usual characteristic of injury followed by redness, soft tissue swelling, pain over involved joint, fracture of cartilage, and muscle tear at knee joint10 could be defined as criteria, which the data were obtained by interview.

Sample size was determined by rule of thumb formula. Total of independent variables were multiplied by 10 . Since this study had three independent variables, 30 minimal samples for each case and control were calculated. Therefore, 60 samples as total minimal samples were defined in this study.11 Since the scales of variables were categorical and all of independent variables were analyzed simultaneously, multivariate logistic regression was used as a statistic analysis in this study. The statistical analysis was adjusted for BMI, parity, and history of knee injury as independent variables towards knee osteoarthritis as dependent variable. Significance test (p), odd ratio (OR), 95\% confidence interval ( $95 \% \mathrm{CI}$ ), and probability were analyzed by logistic regression. Statistic product service solution (SPSS) version 18 was chosen as statistical program in this study.

\section{Results}

From 60 samples as minimal sample size, collecting data in duration about one month had 101 female patients recruited in this study. Forty six samples were included into case group, and another 55 samples were referred as control. Complete data of BMI, parity, and history of knee injury distributed for each case and control.

Samples with obesity were higher in the case group, although there was only one

Table 1 Distribution of Patients Classified by Case and Control

\begin{tabular}{lcccc}
\hline \multirow{2}{*}{ Variables } & \multicolumn{2}{c}{ Osteoarthritis } & \multicolumn{2}{c}{ Non Osteoarthritis } \\
& $(\mathbf{n = 4 6 )}$ & $\mathbf{f ~ ( \% )}$ & $\mathbf{( n = 5 5 )}$ & $\mathbf{f}$ (\%) \\
\hline Obesity & & & & \\
Yes & 26 & 56 & 25 & 45 \\
$\quad$ No & 20 & 44 & 30 & 55 \\
Parity & & & & \\
$\geq 3$ times & 27 & 59 & 15 & 27 \\
$<3$ times & 19 & 41 & 40 & 73 \\
History of knee injury & & & & \\
Yes & 17 & 37 & 6 & 11 \\
No & 29 & 63 & 49 & 89 \\
\hline
\end{tabular}


Table 2 Statistical Value of Knee Osteoarthritis Risk Factors

\begin{tabular}{lcccc}
\hline Variable & $\boldsymbol{\beta}$ & $\mathbf{p ~ ( S i g . )}$ & OR Adjusted & $\mathbf{9 5 \%} \mathbf{C I}$ \\
\hline Phase I & & & & \\
$\quad$ Obesity & 0.28 & 0.549 & 1.32 & $0.52-3.32$ \\
$\quad$ Parity $\geq 3$ times & 1.51 & 0.001 & 4.54 & $1.81-11.34$ \\
$\quad$ History of knee injury & 1.88 & 0.001 & 6.57 & $2.09-20.61$ \\
Constanta $\beta$ & -1.26 & & & \\
Phase II & & & & \\
$\quad$ Parity $\geq 3$ times & 1.54 & 0.001 & 4.7 & $1.89-11.68$ \\
$\quad$ History of knee injury & 1.82 & 0.001 & 6.19 & $2.01-18.99$ \\
Constanta $\beta$ & -2.12 & & & \\
Notes: $\beta=$ value of variable; $\mathrm{p}$ (Sig.)=significance result; OR=odd ratio; CI=confidence interval &
\end{tabular}

sample difference from control group. Parity three times or more and history of knee injury were higher in the group of case (Table 1).

Obesity was not a risk factor of knee osteoarthritis in this study because of $(\mathrm{p}>0.05)$. Although odd ratio (OR) was more than 1,95\% confident interval $(\mathrm{CI})$ reach value 1 meant that obesity was not a risk factor of knee osteoarthritis (OR 1.32; 95\% CI 0.52-3.32).

Parity was a risk factor of knee osteoarthritis in this study because of $(p<0.05)$. Female aged $>50$ years with parity $\geq 3$ times had 4.7 fold risk to knee osteoarthritis (OR 4.7; 95\% CI 1.89-11.68), greater than female aged $>50$ years with parity $<3$ times.

History of knee injury was a risk factor of knee osteoarthritis in this study because of $(p<0.05)$. Female aged $>50$ years with history of knee injury had risk to knee osteoarthritis elevated at 6.19 fold (OR 6.19; 95\% CI 2.0118.99) compared to female aged 50 years without history of knee injury.

Probability in this study was calculated based on formula $\mathrm{p}=1(1+\mathrm{e}-\mathrm{y})$. Since obesity was not significant and not included automatically by backward logistic regression program, analysis of probability was only for knee injury and parity towards knee osteoarthritis. ${ }^{11}$

Female aged $>50$ years with history of parity three times or more and history of knee injury had probability $78 \%$ to suffer from knee osteoarthritis. Then, female aged $>50$ years with history parity $<3$ times and no history of knee injury had probability $10 \%$ to suffer from knee osteoarthritis.

\section{Discussion}

In this study, with case control design, obesity is not a risk factor of knee osteoarthritis.
Obesity in this study, according to health state in this country, is classified by BMI $>27.9$

Different with other cohort study in British, 3035 women underwent examination for BMI, measured 10 times from 2-53 years. Prolonged exposure with obesity from childhood throughout adulthood carried the highest risk to knee osteoarthritis in elderly. ${ }^{12}$

Result from previous study which was established as literatures stated that obesity is a risk factor of knee osteoarthritis. ${ }^{4-6,13}$ The reason of the difference with this study result is this study used case control method and had fewer of samples, different sample size was also might considere different result.

Parity $\geq 3$ times is a risk factor of knee osteoarthritis. The value of OR in this study was high concluding that high elevated the risk $(\mathrm{OR}=4.7)$. For the precision, this result had wide range of $95 \% \mathrm{CI}$, concluding that this study had less precision (95\% CI 1.89-11.68). Although the precision was less, the sample size had complete the minimal requirement (60 samples), instead the samples exceeded the minimal requirement, that was 101 samples.

High frequency of parity is associated with decreasing cartilage volume, predominantly in the tibial compartment and more advance cartilage defected in the patella compartment in population based on sample of female aged 50-80 years. ${ }^{8}$ Frequency of parity is associated with increased risk of having patella cartilage defects, with three or more births having a significantly increased risk of prevalent cartilage defects. These results are consistent with findings in older female, suggesting that parity may play a direct role in the development of knee osteoarthitis. ${ }^{7}$

Indirectly, impact of parity had influence 
in the loss of cartilage volume, while cartilage volume is important substance to protect joint from knee osteoarthritis. Loss of cartilage volume on weight-bearing areas in the knee (especially medial condyle and plateau) was associated with knee osteoarthritis. ${ }^{14}$ Tibiofemoral hyaline articular cartilage loss of volume evidence radiographic joint space narrowing had risk to knee osteoarthritis. ${ }^{15}$

History of knee injury was a risk factor of knee osteoarthritis in this study. According to this study, all types of knee injury were identified, such as redness, swelling, and pain involving the joint cartilage fracture and muscle tear at knee joint. The value of OR in this study was high concluding that high elevated the risk $(\mathrm{OR}=6.19)$. For the precision, this result had wide range of $95 \% \mathrm{CI}$, concluding that this study had less precision (95\% CI 2.01-18.99). Although the precision was less, the sample size completed the minimal requirement $(60$ samples), instead the samples exceeded the minimal requirement, that was 101 samples.

This study has a similar design to casecontrol study conducted in previous studies. Knees with meniscus tears with greater radial involvement and extrusion are at greater risk for later development of knee osteoarthritis. ${ }^{16}$

This result is the same as previous study which stated that knee injury increases the risk to develop knee osteoarthritis. The metaanalysis with twenty four observational studies (20,997 samples) included seven cohorts, five cross sectional and twelve case control studies. Association between history of knee injuries and knee OA was significantly for specified injuries such as inflammation swelling of tissue and redness, ligament or tendon injuries, meniscus damage or menistectomy, and fracture of femur, knee or lower part of the $\operatorname{leg}\left(\mathrm{OR}=5.95,95 \%\right.$ 4.57-7.75). ${ }^{10}$

This study is limited to sample size which only got 101 samples compared to other studies worldwide that acquired thousands sample size. However, it completed the minimal sample size calculated by rule of thumb method. ${ }^{11}$

Another limitation might occur in case control method, such as recall bias and measurement error. To anticipate that problem, confirmation two times in asking question and measurement of BMI is needed.

The strength in this study is all of risk factors which were not analyzed have the same criteria for case and control samples to avoid bias by confounding variable, except for knee malalignment such as varus and valgus. Beside of risk factor, it can be caused by knee osteoarthritis chronically; thus, the association between knee osteoarthritis and knee malalignment should not be defined clearly in this study.

In conclusion, frequency of life birth $\geq 3$ times and history of knee injury are associated with knee injury. On the contrary, obesity is not associated with knee osteoarthritis.

For further study, it needs to identify the obesity in samples that might adjust to lifetime obesity which describes how long the samples have obesity, such as from age groups at teenager or adult with cohort study as established research worldwide.

\section{References}

1. Fansen M, Bridgett L, March L, Hoy D, Penserga E, Brooks P. The epidemiology of osteoarthritis in Asia. Int J Rheum Dis. 2011;14(2):113-21.

2. White $D$, editor. Public health burden, epidemiology, importance of osteoarthritis as a health issue. Proceedings of the 141st American public health association Annual Meeting; 2013 November 2-6; Boston. Massachusetts: APHA; 2013.

3. Zeng QY, Zang $\mathrm{CH}$, Li XF, Dong HY, Zhang AL, Lin L. Associated risk factors of knee osteoarthritis: a population survey in Taiyuan, China. Chin Med J. 2006;119(18):1522-7.

4. Sudoyo AW, Setiyohadi B, Alwi I, Marcellus SK, Setiati S. Buku ajar ilmu penyakit dalam. Jakarta: Interna Publishing; 2009. p. 2538-349.

5. Peter WL, Stephen BZ. Obesity and osteoarthritis. Am J Orthop. 2008;37(3):148-51.

6. Longo DL, Kasper DL, Jameson JL, Fauci AS, Hauser SL, Loscalzo J. Harrison's principle's of internal medicine. 16th ed. New York: McGraw-Hill Medical Publishing; 2005. p. 2038-45.

7. Wei S, Jones G, Venn A, Cicuttini F, March L, Otahal P, et al. The association between parity and knee cartilage in young women. Rheumatology (Oxford). 2012;51(11):2039-45.

8. Wei S, Venn A, Ding C, Martel-Pelletier J, Pelletier JP, Abram F, et al. The associations between parity, other reproductive factors and cartilage in women aged 50-80 years. Osteoarthritis Cartilage. 2011;19(11):1307-13.

9. Kementerian Kesehatan Republik Indonesia. Glosarium: data \& informasi kesehatan. Jakarta: Pusat Data dan 
Informasi Kementerian Kesehatan RI; 2006.

10. Muthuri SG, McWilliams DF, Doherty M, Zhang W. History of knee injuries and knee osteoarthritis: a meta-analysis of observational studies. Osteoarthritis Cartilage. 2011;19(11):1286-93.

11. Dahlan MS. Statistik untuk kedokteran dan kesehatan. 4th ed. Jakarta: Salemba Medika; 2009.

12. Wills AK, Black S, Cooper R, Coppack RJ, Hardy R, Martin KR, et al. Life course body mass index and risk of knee osteoarthritis at the age of 53 years: evidence from the 1946 British birth cohort study. Ann Rheum Dis. 2012;71(5):655-60.

13. Soeroso J, Dans LF, Amarillo ML, Santoso G. Risk factor of symptomatic and a symptomatic osteoarthritis of the knee. Folia Medica Indonesiana. 2005;41(2):118-29.
14. Pelletier JP, Raynauld JP, Berthiaume MJ, Abram F, Choquette D, Haraoui B, et al. Risk factors associated with the loss of cartilage volume on weight-bearing areas in knee osteoarthritis patients assessed by quantitative magnetic resonance imaging: a longitudinal study. Arthritis Res Ther. 2007;9(4):R74.

15. Amin S, LaValley MP, Guermazi A, Grigoryan M, Hunter DJ, Clancy M, et al. The relationship between cartilage loss on magnetic resonance imaging and radiographic progression in men and women with knee osteoarthritis. Arthritis Rheum. 2005;52(10):3152-9.

16. Badlani JT, Borrero C, Golla S, Harner CD, Irrgang JJ. The effects of meniscus injury on the development of knee osteoarthritis data from the osteoarthritis initiative. Am J Sports Med. 2011;41(6):1238-44. 